\section{Thermal inactivation and growth potential of Listeria monocytogenes in smoked tench}

\author{
Raffaella Branciari, ${ }^{1}$ Andrea Valiani, ${ }^{2}$ \\ Raffaella Franceschini, ${ }^{3}$ David Ranucci, ${ }^{1}$ \\ Alessia Lupattelli, ${ }^{1}$ Eleonora Urbani, ${ }^{1}$ \\ Roberta Ortenzi ${ }^{2}$ \\ 'Department of Veterinary Medicine, \\ University of Perugia, Perugia; ${ }^{2}$ Institute \\ for Experimental Veterinary Medicine of \\ Umbria and Marche, Perugia; \\ ${ }^{3}$ Department of Sustainability \\ Engineering, Guglielmo Marconi \\ University, Rome, Italy
}

\begin{abstract}
An experimental study for the evaluation of Listeria monocytogenes inactivation during a hot smoking process in tench was performed using Listeria innocua strains. Furthermore, the survival of $L$. monocytogenes in smoked tench was determined after post-processing in contaminated samples, evaluating the growth potential during storage. $L$. innocua was not detected after the smoking process. In the challenge test, the growth potential of $L$. monocytogenes was 5.68 log colony forming unit $\mathrm{g}^{-1}$. The results showed that hot smoking at an inner temperature around $72^{\circ} \mathrm{C}$ is able to eliminate the microorganism. Nevertheless, the product is able to support the growth of the pathogen if post-process contamination occurs, as the food is suitable for Listeria multiplication. Product recontamination should be prevented by means of appropriate application of hygiene measures.
\end{abstract}

\section{Introduction}

Listeria monocytogenes is a foodborne pathogen that causes a potentially severe foodborne disease with a high mortality rate (CDC, 2013). L. monocytogenes has been observed in a large variety of foods, especially in those that are generally eaten with little or no prior heating (Bremer et al., 2003; Burnett et al., 2005; Bouayad and Hamdi, 2012). Cold smoked seafood has been categorised as one of these high-risk, ready-to-eat (RTE) products because the heat applied during processing is not sufficient to inactivate the organism, and the products are consumed without further cooking (Rocourt et al., 2003; Reij and Den Aantrekker, 2004).
Smoking is an ancient fish preservation method and it has economic importance for the seafood market (Ozogul et al., 2010). As well as providing a specific aroma and colour to the fish, smoking extends the shelf-life of fish due to dehydration, and the antibacterial and antioxidant effects of the smoke components such as formaldehyde, carboxylic acids and phenols (Ozogul et al., 2010; Tocmo et al., 2014). In Umbria region (Italy), smoked tench is an artisanal fish product made by a small fishery consortium along lake Trasimeno and is known to be an economically important fish product which has started to be available in many markets; as a result, it is necessary to investigate the effect of different processing steps in the fish smoking process on the growth potential of $L$. monocytogenes and to determine whether the product supports the growth of $L$. monocytogenes, according to EC Regulation No. 2073/2005 (European Commission, 2005).

The aim of this study was to evaluate the inactivation of $L$. monocytogenes during the hot smoking process in tench, and its survival during storage after post-processing contamination.

\section{Materials and Methods}

\section{Production of smoked tench}

The production of hot smoked tench includes: gutting fish; salting in brine containing $20 \%$ salt for $2 \mathrm{~h}$ at $10^{\circ} \mathrm{C}$; washing to remove the brine; dripping for $16-24 \mathrm{~h}$ at $0 \pm 4^{\circ} \mathrm{C}$; smoking for $6 \mathrm{~h}$ in a convection smoking oven (inner temperature around $72^{\circ} \mathrm{C}$ ); and vacuum packaging. The shelf-life of the vacuum-packaged smoked tench was 30 days at $4^{\circ} \mathrm{C}$, as established by the manufacturer.

\section{Evaluation of Listeria inactivation during the hot smoking process}

The study was performed directly in a fish processing plant. To avoid the use of the pathogen strain, Listeria innocua was used. Before fish contamination, the heat tolerance of a multi-strain mix of $L$. innocua (ATCC $^{\circledR}$ $33090^{\mathrm{TM}}$, Li 1/2015 and Li 2/2015 from the IZS collection and derived from fish fillets) and three strains of $L$. monocytogenes (ATCC $^{\circledR}$ $7644^{\mathrm{TM}}$, Lm 48189/13 and Lm50308/13 from the IZS collection and derived from fish fillets) were compared. This evaluation was carried out as reported by Lorentzen et al. (2010) in order to investigate the suitability of using $L$. innocua as a non-pathogenic indicator.

L. innocua was kept at $-80^{\circ} \mathrm{C}$ in Cryoinstant (VWR Prolabo Chemicals, Leuven, Belgium) and was regenerated into Brain Heart Infusion (BHI) and incubated at $37^{\circ} \mathrm{C}$ for $24 \mathrm{~h}$. Aliquots of each culture were transferred into tubes
Correspondence: David Ranucci, Department of Veterinary Medicine, University of Perugia, via San Costanzo 4, 06126 Perugia, Italy. Tel: +39.075.5857931 - Fax: +39.075 .5857928$

E-mail: david.ranucci@unipg.it

Key words: Listeria monocytogenes; Microbiological challenge test; Smoked tench.

Conflict of interest: the authors declare no potential conflict of interest.

Acknowledgements: the authors would like to thank the Fisheries Consortium of the Lake Trasimeno for providing technical support and advice in formulating experimental smoking tench.

Funding: support for this research was provided by Umbria Region, PSR, Mis. 1.2.4.

Received for publication: 6 May 2016

Revision received: 17 June 2016.

Accepted for publication: 18 June 2016.

This work is licensed under a Creative Commons Attribution-NonCommercial 4.0 International License (CC BY-NC 4.0).

(C) Copyright R. Branciari et al., 2016 Licensee PAGEPress, Italy

Italian Journal of Food Safety 2016; 5:5974 doi:10.4081/ijfs.2016.5974

containing $\mathrm{BHI}$ and incubated at $12 \pm 1^{\circ} \mathrm{C}$, a temperature close to that registered in the processing plant. The stationary phase was reached after 18-20 h. After centrifuging each strain at $2178 \mathrm{~g}$ at $10^{\circ} \mathrm{C}$ for $5 \mathrm{~min}$, the supernatant was discarded and the pellet was resuspended in $10 \mathrm{~mL}$ of sterile physiological solution $\left(\mathrm{H}_{2} \mathrm{O}\right.$ with $\left.0.9 \% \mathrm{NaCl}\right)$. Counts were confirmed by serial decimal dilution and inoculation in Agar Listeria Ottaviani (ALOA Selective Supplement, ALOA Enrichment Supplement; Biolife, Vernon Hills, IL, USA); plates were incubated at $37^{\circ} \mathrm{C}$ for $24-48 \mathrm{~h}$.

The inoculation of tench was performed after brining with a culture mix of $L$. innocua . Before inoculation, tench were screened for Listeria spp. (AFNOR BIO 12/11-03/04; AFNOR, 2010) and were found to be negative. The study was conducted in triplicate (three batches). Brined tench were contaminated with $L$. innocua on the external and internal surfaces before the smoking process with 1\% v/wt of $L$. innocua to a final concentration of $c a .5 \log$ colony forming unit (CFU) $\mathrm{g}^{-1}$. The inoculum was distributed over the entire surface with a sterile L-shaped plastic cell spreader (Incofar, Modena, Italy). The level of contamination was analytically confirmed before the smoking process.

Afterwards, the tench were placed inside the 
smoking chamber. The temperature during the smoking process was logged continuously using a temperature logger (Thermo ButtonPlug; Proges Plus, Willems, France) placed inside five tench located in five different places in the smoking chamber (Figure 1). Temperature data logged for each batch during the smoking process are reported in Figure 2.

After processing, samples were aseptically collected in three different points (head, body and tail) and transferred to the laboratory within 15 ' for the enumeration of $L$. innocua. Briefly, $10 \mathrm{~g}$ of sample of each point was weighed into a sterile stomacher bag, then 90 $\mathrm{mL}$ of peptone water was added. Counts were confirmed by serial decimal dilution and inoculation in ALOA; plates were incubated at $37^{\circ} \mathrm{C}$ for 24-48 h. The reference method (ISO 7218:2007; ISO, 2007) was used for enumeration of bacteria. The typical colonies were tested for biochemical identification in micromethod (API Listeria; BioMérieux, Marcy-l'Étoile, France). The detection of $L$. innocua was also performed using the validated method AFNOR BIO 12/11-03/04 (AFNOR, 2010).

The approach used for calculating death kinetics only referred to thermal inactivation because evaluation of the compounds developed during smoking was not performed. The $\mathrm{D}$ and $\mathrm{z}$ values used were those reported for $L$. monocytogenes by van Asselt and Zwietering (2006). Data were then analysed by software of the Food Safety and Inspection Service of the United States Department of Agriculture (www.fsis.USDA.gov) to evaluate the worstcase scenario for the process. For this evaluation, the D70 value was set at 0.52 and the $\mathrm{z}$ value at $7^{\circ} \mathrm{C}$.

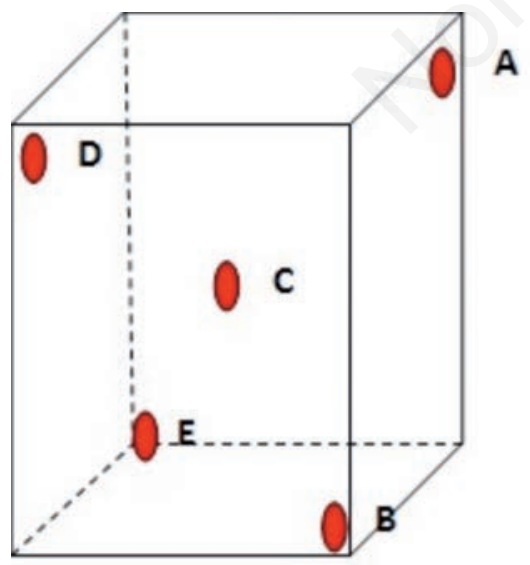

Figure 1. Data logger position inside the smoking chamber. Position of tench containing a data logger: $A$ ) in the top right of the chamber; $B$ ) in the bottom right; $C$ ) in the centre of the chamber; D) in the top left; E) in the bottom left.
Listeria monocytogenes contamination of ready-to-eat tench after smoking process, without further thermal treatment

For the experiment, three batches of vacuum-packaged smoked tench were produced, and each batch consisted of three experimental groups of $2 \mathrm{~kg}$ smoked tench. For the first group (CLm), 12 sample units were produced and contaminated by dipping the smoked tench in a suspension of the above-mentioned multi-strain mix of $L$. monocytogenes. These sample units were used to evaluate the growth potential of $L$. monocytogenes during the product's shelf-life. The cultures were treated as reported before for $L$. innocua. Each of the three strains was combined in an equal quantity at a concentration of about $7 \log \mathrm{CFU} \mathrm{g} \mathrm{g}^{-1}$. Dilutions of the mixed cultures were made to obtain a concentration in the foodstuff that was similar to the concentration occurring in it naturally (Ortenzi et al., 2015). These second stationary-phase subcultures were used for contamination.

For the second group (CTRIZS), 12 units were treated with $1 \% \mathrm{v} / \mathrm{wt}$ of the sterile physiological solution (control samples) in order to compare the products submitted to challenge testing (CLm) with products that were routinely produced. For the first and second group, the smoked tench were kept for $3 \mathrm{~h}$ at $12^{\circ} \mathrm{C}$ after contamination to allow the bacteria to stick onto the fish. The smoked tench were then repacked under vacuum conditions into sterile polyethylene bags. For the third group (CTR), six units were produced following the normal process adopted by the manufacturer in order to compare the products of the second group with products routinely produced by the processor.

In total, 30 smoked tench were sampled during the testing period and submitted to analytical determination. After packaging, the vacu-
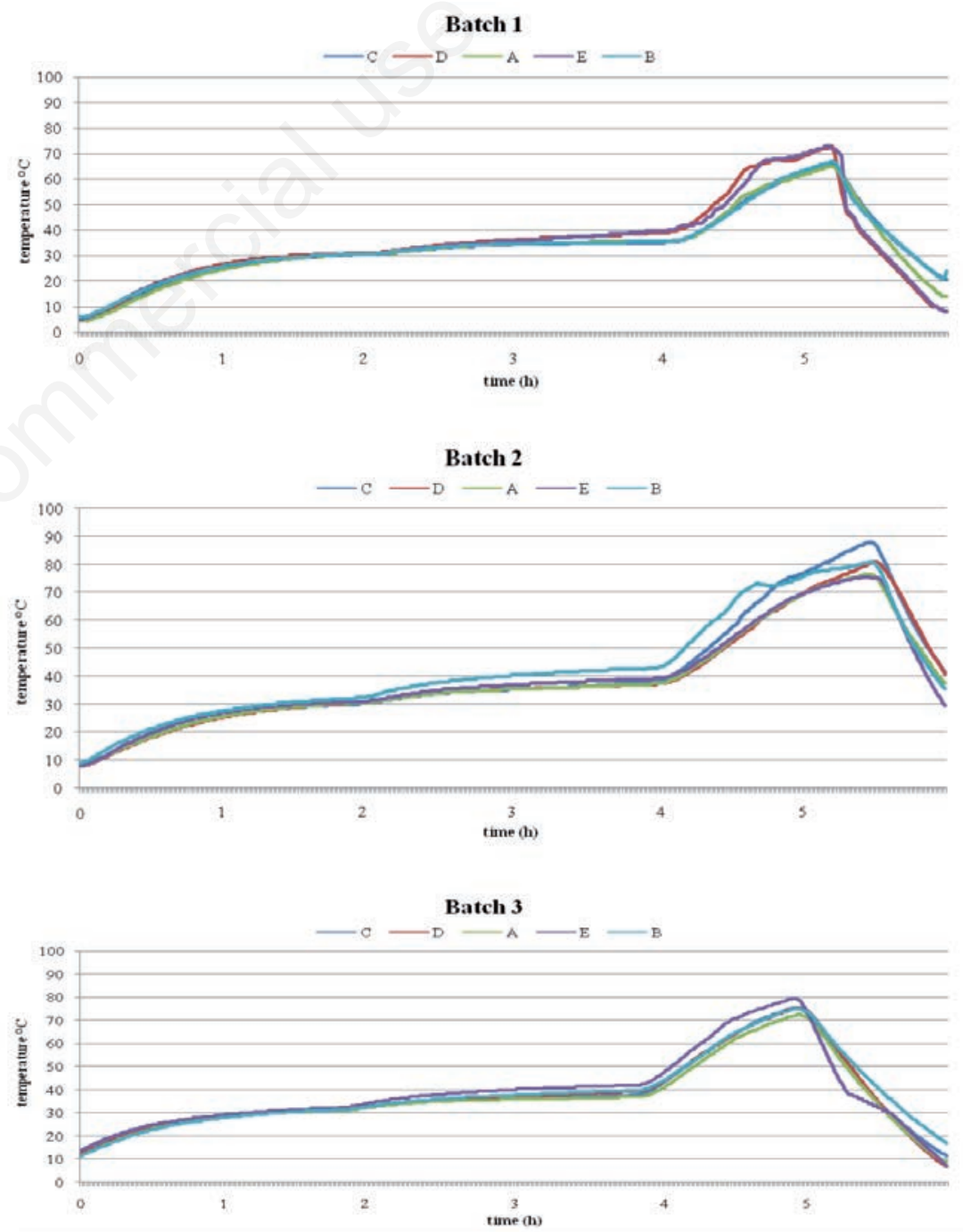

Figure 2. Thermal profile logged in each batch during the smoking process. 
um-packed smoked tench were maintained at $8^{\circ} \mathrm{C}$ for 7 days, and at $12^{\circ} \mathrm{C}$ for the remaining storage time (23 days) (EUCRL, 2008).

The physicochemical determinations of smoked tench were conducted at $0,10,20$ and 30 days of storage time in one-unit samples of each batch (CTRIZS); for the CTR group, analysis was done at 0 and 30 days. The $\mathrm{pH}$ measurements were made using a puncture electrode probe connected to a portable $\mathrm{pH}$ meter (Mettler Toledo Inc., Columbus, $\mathrm{OH}$, USA). The salt content was determined as described by Branciari et al. (2014). Water activity $\left(\mathrm{a}_{\mathrm{w}}\right)$ was measured at $25^{\circ} \mathrm{C}$ with an AquaLab series 3 model TE $\mathrm{a}_{\mathrm{w}}$ recorder (Decagon Devices Inc., Pullman, WA, USA).

The detection and enumeration of $L$. monocytogenes were conducted at $0,10,20$ and 30 days of storage time in all unit samples of each batch according to Annex I of Regulation No. 2073/2005 (European Commission, 2005), using the validated method AFNOR BIO 12/1103/04 (AFNOR, 2010) for detection and EN ISO 11290-2 (ISO, 1996), the reference method for enumeration.

\section{Results and Discussion}

After the smoking process, no $L$. innocua was detected in any of the inoculated samples regardless of batch or position of the tench in the smoking chamber. It has been demonstrated that a smoking process using a temperature of approximately of $30^{\circ} \mathrm{C}$ (cold smoking process) is not sufficient to inactivate this pathogen in smoked salmon (Swaminathan et al., 2007; Porsby et al., 2008). Hence, the chance that $L$. monocytogenes survives and proliferates after the smoking process is rather high. Swaminathan et al. (2007) showed that for $L$. monocytogenes to be inactivated, products must receive heat treatment above $50^{\circ} \mathrm{C}$ and the addition of smoke, which has an antilisterial effect because of its phenolic content.

As shown in Figure 3, software revealed that the experimental treatments were equivalent to a treatment of $70^{\circ} \mathrm{C}$ applied for $2.732 \mathrm{~min}$ and they were able to reduce $L$. monocytogenes by $5.25 \log \mathrm{CFU} \mathrm{g}{ }^{-1}$. The most unfavourable thermal shoulder determined by the software using the temperatures logged is reported in Figure 4. In this worst case scenario, the temperature did not reach $70^{\circ} \mathrm{C}$; nevertheless, the products were at least heated up to 50 min over $50^{\circ} \mathrm{C}$, and this treatment in combination with liquid smoke and brine represented sufficient hurdles to alter the homeostasis of the bacte-

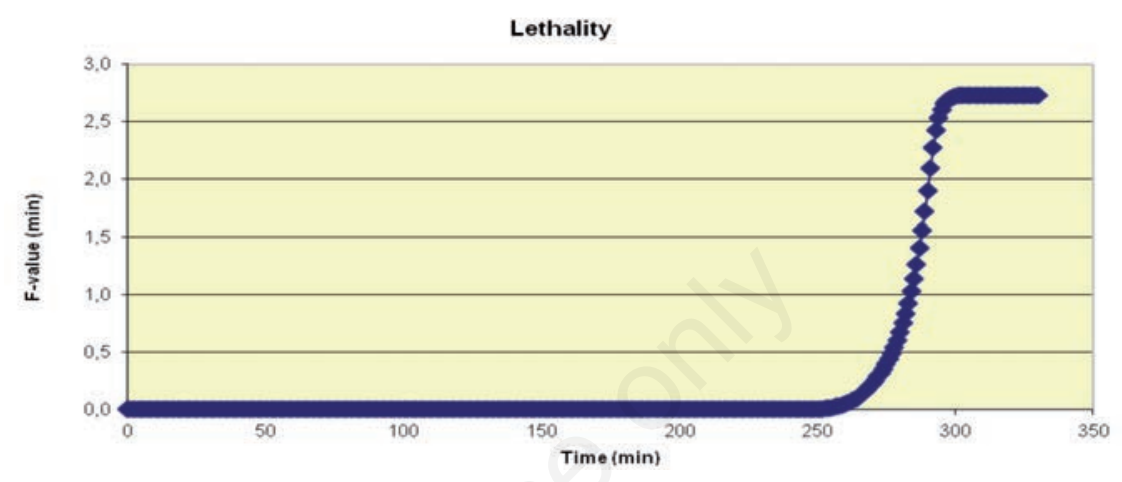

Figure 3. Inactivation of Listeria monocytogenes, thermal and temperature conditions.

Table 1. pH, water activity and sodium chloride of smoked tench during storage.

\begin{tabular}{llcccc}
\multicolumn{5}{c}{} & \multicolumn{5}{c}{ Days of storage } \\
CTR & $\mathrm{pH}$ & $6.02 \pm 0.14$ & nd & nd & $5.95 \pm 0.08$ \\
& $\mathrm{a}_{\mathrm{w}}$ & $0.970 \pm 0.01$ & nd & nd & $0.960 \pm 0.01$ \\
& $\mathrm{NaCl}$ & $2.62 \pm 0.35$ & nd & nd & $2.97 \pm 0.73$ \\
\multirow{2}{*}{ CTRIZS } & $\mathrm{pH}$ & $5.98 \pm 0.08$ & $6.07 \pm 0.13$ & $6.08 \pm 0.08$ & $5.97 \pm 0.07$ \\
& $\mathrm{a}_{\mathrm{w}}$ & $0.973 \pm 0.013$ & $0.71 \pm 0.01$ & $0.97 \pm 0.01$ & $0.963 \pm 0.01$ \\
& $\mathrm{NaCl}$ & $2.53 \pm 0.36$ & $2.58 \pm 0.53$ & $2.61 \pm 0.35$ & $3.02 \pm 0.75$ \\
\hline
\end{tabular}

CTR, third growe: CTRZZS. second growe: a, water activity; $\mathrm{NaCl}$, sodium chloride; nd, not detected. Data represent the average values \pm standard deviation of three replicate samples for three smoked process replicates.

Table 2. Calculation of growth potential of Listeria monocytogenes.

\begin{tabular}{|c|c|c|c|c|c|c|}
\hline Batch & Day & Concentration & SD & Median & Growth potential $(\delta)$ per batch & Highest $\delta$ among the 3 batches \\
\hline 1 & 0 & $\begin{array}{l}2.91 \\
2.88 \\
2.78 \\
8.26 \\
8.20 \\
8.11\end{array}$ & 0.07 & 8.20 & $8.20-2.88=5.32$ & \\
\hline 2 & 0 & $\begin{array}{l}2.90 \\
2.40 \\
2.43 \\
8.11 \\
8.13 \\
8.04\end{array}$ & $\begin{array}{l}0.28 \\
0.05\end{array}$ & 2.43 & $8.11-2.43=5.68$ & 5.68 \\
\hline 3 & $\begin{array}{l}0 \\
30\end{array}$ & $\begin{array}{l}2.58 \\
2.88 \\
2.52 \\
6.62 \\
6.65 \\
7.15\end{array}$ & $\begin{array}{l}0.19 \\
0.29\end{array}$ & $\begin{array}{l}2.58 \\
6.65\end{array}$ & $6.65-2.58=4.07$ & \\
\hline
\end{tabular}

SD, standard deviation. Values are expressed as log CFU g ${ }^{-1}$. 
ria resulting in Listeria inactivation.

The physicochemical characteristics of the smoked tench contaminated after the smoking process (challenge test) and during storage are reported in Table 1. No difference in $\mathrm{pH}, \mathrm{a}_{\mathrm{w}}$ or $\mathrm{NaCl}$ was detected among batches, between the two different sample units (CTRIZS and CTR) or during the storage time.

The results of the behaviour of $L$. monocytogenes during storage are reported in Figure 5. The average pathogen counts in contaminated samples are shown in Table 2. No L. monocytogenes was found in the control sample. During the storage of vacuum-packed smoked tench, L. monocytogenes significantly increased in the inoculated samples. At day 0 , the median concentrations of $L$. monocytogenes were $\log$ $2.88 \mathrm{CFU} \mathrm{g}^{-1}$ (range $\log 2.78-2.91 \mathrm{CFU} \mathrm{g}^{-1}$ ), $\log$ $2.43 \mathrm{CFU} \mathrm{g}^{-1}$ (range 2.40-2.90 $\log \mathrm{CFU} \mathrm{g}^{-1}$ ) and $\log 2.58 \mathrm{CFU} \mathrm{g}^{-1}$ (range 2.52-2.88 $\log \mathrm{CFU} \mathrm{g}^{-1}$ ) for batches 1,2 and 3 , respectively. The standard deviations between the three results at day 0 were $0.23 \log \mathrm{CFU} \mathrm{g}^{-1}$ (batch 1, $0.07 \log$ $\mathrm{CFU} \mathrm{g}^{-1}$; batch 2, $0.28 \log _{\mathrm{CFU} \mathrm{g}}{ }^{-1}$; batch $3,0.19$ $\log$ CFU g ${ }^{-1}$ ). The standard deviation result obtained was always below the value $0.3 \log$
$\mathrm{CFU} \mathrm{g}^{-1}$, set by the technical guidance document (EUCRL, 2008) as the limit to consider the challenge test acceptable due to measurement uncertainty and contamination heterogeneity. The growth potential of $L$. monocytogenes was $5.32 \log \mathrm{CFU} \mathrm{g}^{-1}$ in batch 1, $5.68 \log$ CFU g ${ }^{-1}$ in batch 2, and $4.07 \log \mathrm{CFU} \mathrm{g}^{-1}$ in batch 3 . The maximal difference between the median concentration at day 30 and the median concentration at day $0\left(\log \mathrm{CFU} \mathrm{g}^{-1}\right)$ of each batch was: $=5.68 \log \mathrm{CFU} \mathrm{g}^{-1}$. Considering the results of the present study based on values that were higher than $0.5 \log \mathrm{CFU} \mathrm{g}^{-1}$, it is possible to establish that smoked tench belongs to the category of RTE foods able to support the growth of $L$. monocytogenes in compliance with EC Regulation No 2073/2005 (European Commission, 2005). The multiplication of $L$. monocytogenes showed that refrigeration at 4 to $10^{\circ} \mathrm{C}$ does not prevent the growth of the pathogen in vacuum-packed smoked tench. Other authors indicated that $L$. monocytogenes was also able to grow on various fish products at refrigeration temperatures, and a similar increase was also observed in smoked salmon (Kang et al., 2012; Ferreira et al., 2014).

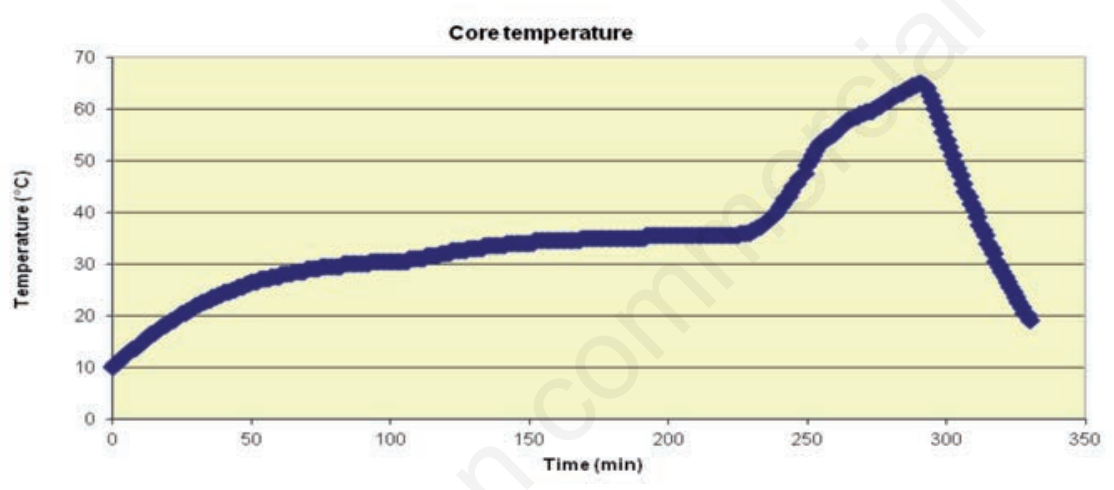

Figure 4. The most unfavourable thermal shoulder determined by the software.

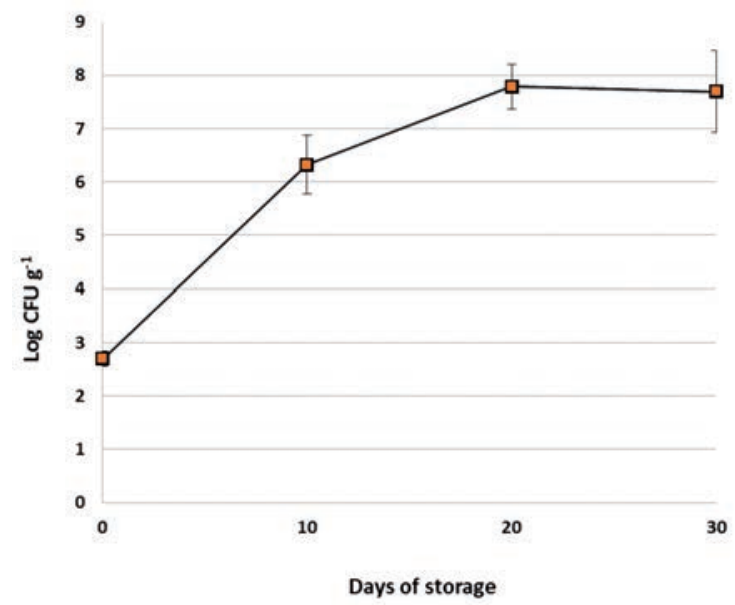

Figure 5. Behaviour of Listeria monocytogenes during storage.

The study confirmed that thermal inactivation of Listeria occurred during the hot smoking process using an appropriate combination of time and temperature. Post-process contamination could be a risk for consumers, as the food is suitable for Listeria multiplication. Thus, product recontamination should be prevented by means of appropriate application of hygiene measures.

\section{References}

AFNOR, 2010. VIDAS Listeria monocytogenes II (VIDAS LM02). Ref. 30704 Enrichment Stage at $37^{\circ} \mathrm{C}, 12 / 11-03 / 04$. Association Française de Normalisation, La Plaine Saint-Denis, France.

Bouayad L, Hamdi TM, 2012. Prevalence of Listeria spp. in ready to eat foods (RTE) from Algiers (Algeria). Food Control 23:397-9.

Branciari R, Mughetti L, Ranucci D, Miraglia D, Valiani A, Acuti G, Trabalza-Marinucci $\mathrm{M}, 2014$. Influence of manufacturing procedure on the compositional and sensory properties of n-3 fatty acid-enriched pecorino cheese. J Dairy Res 81:455-61.

Bremer P, Fletcher G, Osborne C, 2003. Listeria monocytogenes in seafood. New Zealand Institute for Crop and Food Research, Auckland, New Zealand.

Burnett SL, Mertz EL, Bennie B, Ford T, Starobin A, 2005. Growth or survival of Listeria monocytogenes in ready to eat meat products and combination deli salads during refrigerated storage. J Food Sci 70:301-4.

CDC, 2013. Vital signs: Listeria illnesses, deaths, and outbreaks. United States, 2009-2011. MMWR. Morbidity and mortality weekly report 62:448. Centers for Disease Control and Prevention, Atlanta, GA, USA.

EUCRL, 2008. Technical guidance document on shelf-life studies for Listeria monocytogenes in ready-to-eat foods. European Union Community Reference Laboratory for Listeria monocytogenes-French Food Safety Agency ed., Maisons-Alfort, France.

European Commission, 2005. Commission regulation of 15 November 2005 on microbiological criteria for foodstuffs, 2073//2005/EC. In: Official Journal, L 338, $22 / 12 / 2005$.

Ferreira V, Wiedmann M, Teixeira P, Stasiewicz MJ, 2014. Listeria monocytogenes persistence in food-associated environments: epidemiology, strain characteristics, and implications for public health. J Food 
Protect 77:150-70.

ISO, 1996. Microbiology of food and animal feeding stuffs: horizontal method for the detection and enumeration of Listeria monocytogenes. Part 1: detection method. ISO Norm 11290-1:1996. International Organization for Standardization, Geneva, Switzerland.

ISO, 2007. Microbiology of food and animal feeding stuffs. General requirements and guidance for microbiological examinations. ISO Norm 7218:2007. International Organization for Standardization, Geneva, Switzerland.

Kang J, Tang S, Liu RH, Wiedmann M, Boor KJ, Bergholz TM, Wang S, 2012. Effect of curing method and freeze-thawing on subsequent growth of Listeria monocytogenes on cold-smoked salmon. J Food Protect 75:1619-26.

Lorentzen G, Olsen RL, Bjørkevoll I, Mikkelsen H, Skjerdal T, 2010. Survival of Listeria innocua and Listeria monocytogenes in muscle of cod (Gadus morhua L.) during salt-curing and growth during chilled storage of rehydrated product. Food Control 3:292-7.

Ortenzi R, Branciari R, Primavilla S, Ranucci D, Valiani A, 2015. Behaviour of Listeria monocytogenes in artisanal raw milk Pecorino Umbro cheese: a microbiological challenge test. Ital J Food Safety 4:169-71.

Ozogul Y, Ozogul F, Kuley E, 2010. Effects of combining of smoking and marinating on the shelf life of anchovy stored at $4^{\circ} \mathrm{C}$. Food Sci Biotechnol 19:69-75.

Porsby CH, Vogel BF, Mohr M, Gram L, 2008. Influence of processing steps in coldsmoked salmon production on survival and growth of persistent and presumed nonpersistent Listeria monocytogenes. Int $\mathrm{J}$ Food Microbiol 122:287-95.

Reij MW, Den Aantrekker ED, 2004. Recontamination as a source of pathogens in processed foods. Int $\mathrm{J}$ Food Microbiol 91:1-11.
Rocourt J, Ben Embarek P, Toyofuku H, Schlundt J, 2003. Quantitative risk assessment of Listeria monocytogenes in readyto-eat foods: the FAO/WHO approach. Fems Immunol Med Microbiol 35:263-7.

Swaminathan B, Cabanes D, Zhang W, Cossart P, 2007. Listeria monocytogenes. In: Doyle MP, Buechat LR, eds. Food microbiology. Fundamentals and frontiers. American Society for Microbiology (ASM) Pres, Washington, DC, USA. pp 457-92.

Tocmo R, Krizman K, Khoo WJ, Phua LK, Kim M, Yuk HG, 2014. Listeria monocytogenes in vacuum packed smoked fish products: occurrence, routes of contamination, and potential intervention measures. Compr Rev Food Sci Food Saf 13:172-89.

van Asselt E, Zwietering M, 2006. A systematic approach to determine global thermal inactivation parameters for various food pathogens. Int J Food Microbiol 107:73-82. 